\title{
is Research Square \\ Lung cancer as a risk factor for abdominal aortic aneurysm
}

Hyeran Gwon

Yonsei University

Du-Young Kang

Sungkyunkwan University

Seong Yong Park

Sungkyunkwan University

Jun Seong Kwon

Charm Vascular Clinic

Sang Hoon Lee ( $\sim$ cloud9@yuhs.ac)

Yonsei University

\section{Research Article}

Keywords: Carcinoma, Non-Small Cell Lung Cancer, Aortic Aneurysm, Abdominal, Risk Factors

Posted Date: March 22nd, 2022

DOI: https://doi.org/10.21203/rs.3.rs-1357841/v2

License: @ (i) This work is licensed under a Creative Commons Attribution 4.0 International License.

Read Full License 


\section{Abstract \\ Background}

Lung cancer and abdominal aortic aneurysm (AAA) have several common risk factors. Considering that AAA is fatal, precise diagnosis and management of AAA would result in long-term survival benefit in patients with early lung cancer with good prognosis. We aimed to assess the prevalence and characteristics of AAA in patients with resectable non-small cell lung cancer (NSCLC).

\section{Methods}

Between January 2019 and November 2020, 1,019 patients with primary NSCLC treated surgically in Severance and Kangbuk Samsung Hospitals were reviewed retrospectively. We re-read abdominal-pelvic computed tomography (APCT) and positron emission tomography (PET) images and evaluated the presence of AAA. The control group comprised 2,899 cancer-free people who had a health check-up CT scan in Severance between January 2018 and December 2019. The Institutional Review Board and Ethics Committee of Severance Hospital approved this study (IRB number: 4-2021-1430).

\section{Results}

Among patients with resectable primary NSCLC patients, 39/1,019 (3.8\%; odds ratio [OR], 19.19; 95\% confidence interval [Cl], 8.10-46.46) had AAA compared with 6/2,899 $(0.2 \%)$ in the control $(P<0.001)$. Smokers were more likely to have AAA than non-smokers (7.0\% vs $0.8 \%$; OR, 9.57; 95\% Cl, 3.38-27.14; $\mathrm{P}<$ 0.001). In multivariable regression analysis, male sex (OR, 13.24; $95 \% \mathrm{Cl}, 1.50-117.48 ; \mathrm{P}=0.020)$, older age $(\mathrm{OR}, 1.10 ; 95 \% \mathrm{Cl}, 1.04-1.15 ; \mathrm{P}<0.001)$, current smoker status $(\mathrm{OR}, 4.20 ; 95 \% \mathrm{Cl}, 1.20-14.62 ; \mathrm{P}=$ $0.024)$, and coronary artery obstructive disease $(\mathrm{OR}, 3.13 ; 95 \% \mathrm{Cl}, 1.48-6.62 ; \mathrm{P}=0.003)$ were independent risk factors for AAA development in lung cancer.

\section{Conclusions}

In our real-world study, patients with early lung cancer has a significantly higher prevalence of AAA than cancer-free controls, indicating they are a high-risk group for AAA. Therefore, we suggest patients with early NSCLC, especially smokers older than 60 years, undergo regular AAA surveillance with long term post-op follow-up for not only lung cancer but also AAA.

\section{Background}

An abdominal aortic aneurysm (AAA) is defined as dilatation of the abdominal aorta to more than $3.0 \mathrm{~cm}$ in diameter. Although the incidence and prevalence of AAA is low, the mortality of ruptured AAA is very high; $59-83 \%$ of patients with ruptured AAA die before they can be admitted to hospital. The mortality 
rate of emergent surgery after rupture is more than $40 \%$, and only $10-25 \%$ of them are likely to survive until discharge.[1] [2] The growth rate and risk of rupture in AAA increase proportionally to the diameter, which increases over time. Therefore, patients with AAA on initial screening are recommended to undergo regular surveillance every 6 months to 3 years, depending on the aneurysm size.[3] Because the regular surveillance and a timely intervention are important for survival in high risk patients for AAA.

Lung cancer is one of the most common cancer in worldwide and the death rate is relatively higher than other cancers. The 5 -year survival rate for early stage lung cancer is $59 \%$ whereas that of advanced lung cancer is $6 \%$.[4] The number of patients with early stage lung cancer has increased owing to early diagnosis using low-dose computed tomography (LDCT) screening.[5] Consequently, the proportion of patients with resectable lung cancer has increased, and the prognosis of lung cancer has also improved. [6]

Several risk factors of AAA, including smoking, male sex, older age, hypertension, dyslipidemia, coronary artery obstructive disease (CAOD), and chronic obstructive pulmonary disease (COPD), are also risk factors of lung cancer.[7] [8] [9]

It is unclear whether AAA surveillance is beneficial for patients with advanced lung cancer whose life expectancy is short. However, early detection and active monitoring of AAA would be beneficial for longterm survival in patients with early lung cancer because AAA rupture can be fatal, and the prognosis of early lung cancer is good.

Positron emission tomography-computed tomography (PET-CT), which includes non-contrast abdominalpelvic computed tomography (APCT), is used for clinical staging of lung cancer. Therefore, whether AAA is present in patients with lung cancer who are candidates for curative surgery can be verified.

We aimed to examine the prevalence of AAA and its characteristics in patients with early lung cancer who were eligible for resection.

\section{Methods}

\section{Patients}

From January 2019 to November 2020, 1,391 patients underwent lung cancer resection at Severance Hospital and Kangbuk Samsung Hospital. Among them, 372 patients with primary non-small cell lung cancer (NSCLC) without abdominal imaging (APCT and PET-CT) or underwent palliative surgery were excluded from the analysis. A total of 1,019 patients with primary NSCLC who underwent lung cancer resection were reviewed retrospectively. Demographic and risk factor data (age, sex, smoking history, body mass index [BMI], and comorbidities such as hypertension , diabetes mellitus, dyslipidemia, COPD, CAOD, peripheral artery occlusive disease [PAOD], and chronic kidney disease [CKD]) were extracted from electronic medical records. Current smokers were defined as those who still smoked at the time of lung 
cancer diagnosis, and former smokers were defined as those who stopped smoking before the diagnosis of lung cancer. Histologic types and stages of lung cancer were also analyzed.

We also obtained data from a control group consisting of people who underwent a health check-up CT scan in Severance between January 2018 and December 2019 to compare the prevalence of AAA between the lung cancer and general populations. There were a total of 2,899 participants in the cancerfree control group. Among them, we excluded those with malignancy of any type. The Institutional Review Board and Ethics Committee of Severance Hospital approved this study (IRB number: 4-2021-1430).

\section{Measurement of AAA}

We retrospectively re-read and measured the diameter of the abdominal aorta on all patients' APCT and PET-CT. The maximum aneurysm diameter of the abdominal aorta derived from abdominal imaging was based on the outer wall-to-outer wall distance in the plane perpendicular to the path of the aorta. An aneurysm was defined as an aortic diameter $>3.0 \mathrm{~cm}$.[10]

\section{Statistical analysis}

Continuous variables are expressed as mean \pm SD and categorical variables are presented as percentage value ( $\mathrm{n} /$ total). The comparison of the prevalence of AAA between the lung cancer and cancer-free control groups was analyzed using the Pearson $\chi^{2}$ test. We analyzed the independent associations of multiple variables as a risk factor of AAA in patients with lung cancer using a univariable logistic regression model. Using factors that were significantly related to the development of AAA in lung cancer in the univariable logistic regression analysis, we assessed the independent risk factors of AAA in NSCLC with multivariable logistic regression analysis. Adjusted odds ratios (ORs) with associated $95 \%$ confidence intervals (Cls) were calculated. An adjusted P-value $<0.05$ was considered statistically significant. All statistical analysis were performed using SPSS version 26 (SPSS, Chicago, IL, USA).

\section{Results}

\section{Baseline characteristics}

Among the 1019 patients with primary NSCLC who underwent lung resection, the mean age was 64.2 years (standard deviation 9.6 years), 56.0\% $(571 / 1,019)$ were male. 33.6\% $(342 / 1,019)$ were former smokers and $15.8 \%(161 / 1019)$ were current smokers. The most common cancer stage was stage I $(74.2 \%, 756 / 1,019)$. The most common cancer type was adenocarcinoma $(81.8 \%, 834 / 1,019)$. Table 1 gives more information about other risk factors for AAA, histologic data, and cancer stage.

\section{AAA prevalence in smokers (former and current) and non-smokers}

In total, $49.4 \%(503 / 1,019)$ of lung cancer patients had a positive smoking history. The mean number of smoking pack-years (PY) was 19.6 PY. A significantly higher proportion of smokers than non-smokers had AAA (7.0\% [35/503] vs. 0.8\% [4/516]; OR, 9.53; 95\% Cl, 3.38-27.14; P<0.001; Table 2). 
The prevalence of AAA was 3.8\% $(39 / 1,019)$ in the lung cancer group and $0.2 \%(6 / 2,899)$ in the control group. Using the Pearson $\chi^{2}$ test, the lung cancer group had a significantly higher prevalence of AAA than the control group (OR, 19.19; 95\% Cl, 8.10-46.46; $\mathrm{P}<0.001$; Table 3). In terms of AAA risk factors between the two groups, the mean age in the lung cancer group was significantly higher than that in the control group ( $64.2 \pm 9.6$ vs. $54.4 \pm 10.3$ years, $P<0.001$; Table 3 ). As older age is an important risk factor for AAA development, this difference may have contributed to the higher prevalence of AAA in the lung cancer group. However, multivariable logistic regression analysis revealed that the prevalence of AAA was 10fold higher in the lung cancer group than in the cancer-free control group, even after adjusting for age, sex, smoking history, and other AAA risk factors (Table 4), indicating that lung cancer is also an independent risk factor for AAA development.

\section{Risk factors for AAA development in patients with lung cancer}

In the univariable logistic regression analysis, male sex (OR, 31.87; 95\% $\mathrm{Cl}, 4.36-233.03, \mathrm{P}=0.001)$, increasing age $(\mathrm{OR}, 1.10 ; 95 \% \mathrm{Cl}, 1.05-1.15, \mathrm{P}<0.001)$ and especially age $>60$ years $(\mathrm{OR}, 17.33 ; 95 \% \mathrm{Cl}$, 2.37-126.83), smoking history (OR, 9.57; 95\% Cl, 3.38-27.14, $\mathrm{P}<0.001)$, smoking $P Y(O R, 1.02 ; 95 \% \mathrm{Cl}$ $1.01-1.03, \mathrm{P}<0.001)$, HTN (OR, 3.15; 95\% Cl 1.65-7.09, $\mathrm{P}=0.001)$, COPD (OR, 7.22; 95\% Cl, 3.74-13.93, $P<0.001)$, CAOD (OR, 5.13; $95 \% \mathrm{Cl}, 2.55-10.35, P<0.001)$, CKD stage $(P=0.004)$, and lung cancer pathology (squamous lung cancer, $\mathrm{OR}, 3.16 ; 95 \% \mathrm{Cl}, 1.57-6.35, \mathrm{P}=0.005$ ) were independent risk factors for AAA in lung cancer (Table 4). We analyzed the independent contributing factors to higher AAA prevalence in lung cancer using multivariable logistic regression of the significant AAA risk factors identified in the univariable analysis. Because smoking history (yes/no), smoking amount (PY), and COPD have a common factor of smoking and are closely related to each other, we only used smoking history (yes/no) in the multivariable logistic regression analysis. Male sex (OR, 13.238; $95 \% \mathrm{Cl}, 1.492-$ 117.482; $P=0.020)$, increasing age $(O R, 1.10 ; 95 \% \mathrm{Cl}, 1.04-1.15 ; P<0.001)$, smoking history $(P=0.021)$, and CAOD $(O R, 3.13 ; 95 \% \mathrm{Cl}, 1.48-6.62 ; \mathrm{P}=0.003)$ were independent risk factors for $A A A$ in lung cancer in the multivariable logistic regression model (Table 5).

\section{Discussion}

We observed that patients with early lung cancer had a significantly higher prevalence of AAA than that of the general population. Old age (especially $>60$ years), male sex, smoking history, and CAOD were independent risk factors for AAA development in patients with lung cancer. The significant association between AAA and early lung cancer suggests a potential benefit for optimized screening for AAA in patients with lung cancer eligible for lung resection surgery.

The key pathologic characteristics of AAA include vascular inflammation, oxidative stress, destruction of the aortic extracellular matrix (ECM), and thinning of the aortic wall from loss of vascular smooth muscle cells.[11] The risk factors for AAA in lung cancer we identified would contribute in some way to the 
pathophysiology of AAA. Male sex is a well-known major predisposing factor (4-6 times more prevalent in men) in AAA development, consistent with our result. Previous studies found that endogenous sex hormone signalling contributed to sex differences in AAA; androgens stimulate key pathological processes in AAA, while oestrogen inhibits these processes.[12] Moreover, CAOD and AAA are closely related; the prevalence of CAOD in AAA is significantly higher than that in the general population and vice versa.[13] It is unclear whether the strong association is simply due to shared risk factors or if there are other causes beyond that.[14] Smoking is a predominant risk factor for not only lung cancer but also AAA. Smoking is known to have a positive relationship with incremental increased growth rate of AAA up to $0.4 \mathrm{~mm}$ per year.[15] Moreover, there is a dose-dependent relationship between smoking and AAA; it has been shown that smoking duration and total lifetime smoking exposure both directly correlate with increased risk of AAA.[16]

In our study, AAA prevalence in smokers was 9-fold higher than that in non-smokers, which is much higher than previously reported results (2-5-fold),[17] [18] although the pattern is consistent with previous reports that smoking is an important risk factor for developing AAA.[19] [20] That might be because in our study group, patients with lung cancer were highly likely to be heavy smokers. Moreover, in our study, smoking amount showed a dose-dependent relationship with the prevalence rate of AAA in patients with lung cancer (OR, 1.02; 95\% Cl, 1.01-1.03; $\mathrm{P}<0.001$; Table 4), similar to previous study results.[17] Since AAA diameter increases over time, age is also a risk factor, as certain intrinsic damage to the aortic vasculature that contributes to AAA development also accumulates with advancing age in patients with lung cancer.

Although the prevalence of AAA in patients with lung cancer was significantly higher than that in our control group, it was lower than that previously reported (3.8\% vs. $11.1 \%$ ).[21] Even among patients with lung cancer aged $>65$ years, the prevalence of AAA was $6 \%$. This could be because AAA prevalence is lower in Asians than in Caucasians.[22] Another possible reason is that the study population of previous studies included higher proportions of patients with advanced lung cancer, squamous cell lung cancer, and small cell lung cancer, which are known to be associated with heavy smoking.[23] Furthermore, almost half of our study population were never smokers. In the univariable logistic regression model, squamous cell lung cancer was related to higher risk of AAA development than adenocarcinoma. This might be related to squamous cell lung cancer being more strongly related than adenocarcinoma to smoking.[24]

Current guidelines recommend interventional treatment (surgical or endovascular repair) only when the AAA diameter exceeds $5.5 \mathrm{~cm}$. For small AAAs $(3.0-5.4 \mathrm{~cm})$, regular monitoring with ultrasonography or CT regularly based on its diameter is recommended.[25] Former smokers who quit smoking for $>25$ years have similar relative risk of developing AAA as that of never smokers.[26] Furthermore, there is a decline in risk of AAA of approximately $30 \%$ for each decade after quitting.[17] Thus, smoking cessation is important with respect to not only lung cancer, but also AAA surveillance and reducing the growth rate of AAA. 
Several studies have investigated medications for AAA aimed at reducing aortic inflammation and proteolysis and supporting vascular smooth muscle cell recovery. However, there is no strong scientific evidence that supports pharmacological treatment to reduce AAA growth in humans[27] [28]; the benefit of pharmacologic therapies, such as statins,[29] antihypertensive drugs (beta blockers and angiotensinconverting enzyme inhibitors),[30] [31] metformin,[32] and antibiotics (roxithromycin and doxycycline), [33] [34] in preventing rupture in small AAAs is controversial. However, there is some evidence that high blood pressure increases the risk of developing AAA.[35] Therefore, strict control of blood pressure in patients with lung cancer with AAA might be helpful as a preventive strategy for AAA complications.

Based on the proven cost-effective benefit of population-based AAA screening programs in high-risk groups,[2] the US Preventive Services Task Force (USPSTF) recommends screening with ultrasonography for patients at high risk of AAA (men 65 to 75 years of age with a history of smoking). A previous study found that AAA prevalence is higher in patients with lung cancer.[21] In our study, the prevalence of AAA was also significantly higher in the resectable lung cancer group, indicating that patients with lung cancer are at high risk of AAA. Unlike previous studies, we evaluated the prevalence of AAA in patients with early lung cancer, where the life expectancy is much longer, which will lead to greater benefit from timely AAA management in preventing acute emergencies and subsequent fatalities due to rupture of AAAs. In our real-world database, only 6 out of 39 patients with lung cancer with AAA were diagnosed with AAA and managed by clinicians. The majority of AAAs in patients with lung cancer $(84.6 \% ; 33 / 39)$ were ignored without risk management to prevent AAA rupture.

There are several limitations of this study. First, there was limited information on family history of vascular disease and lung cancer because our database was retrospectively analyzed. Genetic factors and family history are well-known risk factors for both lung cancer[36] and AAA.[37] Therefore, family history of lung cancer or AAA may be important risk factors for AAA in patients with lung cancer. Second, the prevalence of AAA in the cancer-free group was lower than the general prevalence of AAA in Asian populations.[22] That might be related to characteristics of our study population; the cancer-free control group were younger (mean age 54.4) than 65 years, which is the cut-off age for AAA surveillance.[38] In addition, those who voluntarily undergo regular health check-ups are likely to have a healthier lifestyle, including smoking cessation.

\section{Conclusions}

In conclusion, our finding indicates that patients with early lung cancer are a high-risk group for AAA and require AAA surveillance. Therefore, we suggest patients with early lung cancer, especially those with a smoking history and older than 60 years, are considered for regular surveillance for AAA. Furthermore, they should be educated to stop smoking and control blood pressure strictly to correct modifiable risk factors of AAA. In future studies, there is a need to evaluate the cost-effectiveness of the benefits of AAA surveillance in patients with lung cancer. In addition, further studies on medications to reduce aortic inflammation and proteolysis and enhance vascular smooth muscle cell recovery to reduce complication of AAA are required. 


\section{Abbreviations}

AAA, abdominal aortic aneurysm; BMI, body max index; HTN, hypertension; DM, diabetes mellitus; COPD, chronic obstructive pulmonary disease; CAOD, coronary artery obstructive disease; PAOD, peripheral arterial occlusive disease; NSCLC, non-small cell lung cancer; SCC, squamous cell carcinoma; CKD, chronic kidney disease; $\mathrm{Cl}$, confidence interval; OR, odds ratio; PY, pack years; $y / n$, yes/no; APCT, abdominal-pelvic computed tomography; PET, positron emission tomography

\section{Declarations}

\section{Ethics approval and consent to participate}

This study was performed in accordance with the Declaration of Helsinki. This human study was approved by The Institutional Review Board and Ethics Committee of Severance Hospital - approval (IRB number: 4-2021-1430). All parents, guardians or next of kin provided written informed consent for the minors to participate in this study.

\section{Consent for publication}

Not applicable

\section{Availability of data and materials}

The datasets used and/or analyzed during the current study are available from the corresponding author on reasonable request.

\section{Competing interests}

The authors declare that they have no competing interests.

\section{Funding}

none

\section{Authors' contributions}

Concept and design of the study by Sang Hoon Lee. Data collection and management by Hye Ran Gwon, Seong Yong Park, Jun Seong Kwon, Sang Hoon Lee. Statistical analysis and drafting of the manuscript by Hye Ran Gwon. Review and final approval of the manuscript by all the authors. All authors read and approved the final manuscript.

Acknowledgements: none

\section{References}


1. Bengtsson $\mathrm{H}$, Bergqvist $\mathrm{D}$ : Ruptured abdominal aortic aneurysm: a population-based study. $J$ VasC Surg1993, 18:74-80.

2. Daroudi R, Shafe O, Moosavi J, Salimi J, Bayazidi Y, Zafarghandi MR, Maleki M, Moini M, Farshidmehr P, Sadeghipour P: Cost-effectiveness of a population-based AAA screening program for men over 65 years old in Iran. Cost Effectiveness and Resource Allocation2021, 19:29.

3. Hirsch Alan T, Haskal Ziv J, Hertzer Norman R, Bakal Curtis W, Creager Mark A, Halperin Jonathan L, Hiratzka Loren F, Murphy William RC, Olin Jeffrey W, Puschett Jules B, et al: ACC/AHA 2005 Guidelines for the Management of Patients With Peripheral Arterial Disease (Lower Extremity, Renal, Mesenteric, and Abdominal Aortic): Executive Summary A Collaborative Report From the American Association for Vascular Surgery/Society for Vascular Surgery, 邓Society for Cardiovascular Angiography and Interventions, Society for Vascular Medicine and Biology, Society of Interventional Radiology, and the ACC/AHA Task Force on Practice Guidelines (Writing Committee to Develop Guidelines for the Management of Patients With Peripheral Arterial Disease). Journal of the American College of Cardiology2006, 47:1239-1312.

4. Siegel RL, Miller KD, Fuchs HE, Jemal A: Cancer Statistics, 2021. CA: A Cancer Journal for Clinicians2021, 71:7-33.

5. Aberle DR, Adams AM, Berg CD, Black WC, Clapp JD, Fagerstrom RM, Gareen IF, Gatsonis C, Marcus PM, Sicks JD: Reduced lung-cancer mortality with low-dose computed tomographic screening. $N$ Engl J Med2011, 365:395-409.

6. Bach PB, Jett JR, Pastorino U, Tockman MS, Swensen SJ, Begg CB: Computed Tomography Screening and Lung Cancer Outcomes. JAMA2007, 297:953-961.

7. Hernesniemi JA, Vänni V, Hakala $T$ : The prevalence of abdominal aortic aneurysm is consistently high among patients with coronary artery disease. J Vasc Surg2015, 62:232-240.e233.

8. Xiong J, Wu Z, Chen C, Guo W: Chronic obstructive pulmonary disease effect on the prevalence and postoperative outcome of abdominal aortic aneurysms: A meta-analysis. Scientific Reports2016, 6:25003.

9. Malhotra J, Malvezzi M, Negri E, La Vecchia C, Boffetta P: Risk factors for lung cancer worldwide. Eur Respir J2016, 48:889-902.

10. Chaikof EL, Dalman RL, Eskandari MK, Jackson BM, Lee WA, Mansour MA, Mastracci TM, Mell M, Murad MH, Nguyen LL, et al: The Society for Vascular Surgery practice guidelines on the care of patients with an abdominal aortic aneurysm. J Vasc Surg2018, 67:2-77.e72.

11. Liu B, Granville DJ, Golledge J, Kassiri Z: Pathogenic mechanisms and the potential of drug therapies for aortic aneurysm. American Journal of Physiology-Heart and Circulatory Physiology2020, 318:H652-H670.

12. Boese AC, Chang L, Yin K-J, Chen YE, Lee J-P, Hamblin MH: Sex differences in abdominal aortic aneurysms. American Journal of Physiology-Heart and Circulatory Physiology2018, 314:H1137H1152. 
13. Elkalioubie A, Haulon S, Duhamel A, Rosa M, Rauch A, Staels B, Susen S, Van Belle E, Dupont A: Meta-Analysis of Abdominal Aortic Aneurysm in Patients With Coronary Artery Disease. Am J Cardio/2015, 116:1451-1456.

14. Van Kuijk JP, Flu WJ, Dunckelgrun M, Bax JJ, Poldermans D: Coronary artery disease in patients with abdominal aortic aneurysm: a review article. J Cardiovasc Surg (Torino)2009, 50:93-107.

15. Sweeting MJ, Thompson SG, Brown LC, Powell JT: Meta-analysis of individual patient data to examine factors affecting growth and rupture of small abdominal aortic aneurysms. Br J Surg2012, 99:655-665.

16. Kent KC, Zwolak RM, Egorova NN, Riles TS, Manganaro A, Moskowitz AJ, Gelijns AC, Greco G: Analysis of risk factors for abdominal aortic aneurysm in a cohort of more than $\mathbf{3}$ million individuals. Journal of Vascular Surgery2010, 52:539-548.

17. Norman PE, Curci JA: Understanding the effects of tobacco smoke on the pathogenesis of aortic aneurysm. Arterioscler Thromb Vasc Bio/2013, 33:1473-1477.

18. Lederle FA, Johnson GR, Wilson SE, Chute EP, Hye RJ, Makaroun MS, Barone GW, Bandyk D, Moneta GL, Makhoul RG: The aneurysm detection and management study screening program: validation cohort and final results. Aneurysm Detection and Management Veterans Affairs Cooperative Study Investigators. Arch Intern Med2000, 160:1425-1430.

19. Jahangir E, Lipworth L, Edwards TL, Kabagambe EK, Mumma MT, Mensah GA, Fazio S, Blot WJ, Sampson UK: Smoking, sex, risk factors and abdominal aortic aneurysms: a prospective study of 18 782 persons aged above 65 years in the Southern Community Cohort Study. $J$ Epidemiol Community Health2015, 69:481-488.

20. Stackelberg O, Wolk A, Eliasson K, Hellberg A, Bersztel A, Larsson SC, Orsini N, Wanhainen A, Björck M: Lifestyle and Risk of Screening-Detected Abdominal Aortic Aneurysm in Men. J Am Heart Assoc2017, 6.

21. Wiles B, Comito M, Labropoulos N, Santore LA, Bilfinger T: High prevalence of abdominal aortic aneurysms in patients with lung cancer. J Vasc Surg2021, 73:850-855.

22. Salem MK, Rayt HS, Hussey G, Rafelt S, Nelson CP, Sayers RD, Naylor AR, Nasim A: Should Asian Men be Included in Abdominal Aortic Aneurysm Screening Programmes? European Journal of Vascular and Endovascular Surgery2009, 38:748-749.

23. Rudin CM, Brambilla E, Faivre-Finn C, Sage J: Small-cell lung cancer. Nature Reviews Disease Primers2021, 7:3.

24. Khuder SA: Effect of cigarette smoking on major histological types of lung cancer: a meta-analysis. Lung Cancer2001, 31:139-148.

25. Keisler B, Carter C: Abdominal aortic aneurysm. Am Fam Physician2015, 91:538-543.

26. Aune D, Schlesinger S, Norat T, Riboli E: Tobacco smoking and the risk of abdominal aortic aneurysm: a systematic review and meta-analysis of prospective studies. Scientific Reports2018, 8:14786. 
27. Guessous I, Periard D, Lorenzetti D, Cornuz J, Ghali WA: The efficacy of pharmacotherapy for decreasing the expansion rate of abdominal aortic aneurysms: a systematic review and metaanalysis. PLoS One2008, 3:e1895.

28. Golledge J, Moxon JV, Singh TP, Bown MJ, Mani K, Wanhainen A: Lack of an effective drug therapy for abdominal aortic aneurysm. Journal of Internal Medicine2020, 288:6-22.

29. Rahman MN, Khan JA, Mazari FA, Mockford K, McCollum PT, Chetter IC: A randomized placebo controlled trial of the effect of preoperative statin use on matrix metalloproteinases and tissue inhibitors of matrix metalloproteinases in areas of low and peak wall stress in patients undergoing elective open repair of abdominal aortic aneurysm. Ann Vasc Surg2011, 25:32-38.

30. West MA, Parry M, Asher R, Key A, Walker P, Loughney L, Pintus S, Duffy N, Jack S, Torella F: The Effect of beta-blockade on objectively measured physical fitness in patients with abdominal aortic aneurysms-A blinded interventional study. $\mathrm{Br} J$ Anaesth2015, 114:878-885.

31. Morris DR, Cunningham MA, Ahimastos AA, Kingwell BA, Pappas E, Bourke M, Reid CM, Stijnen T, Dalman RL, Aalami OO, et al: TElmisartan in the management of abDominal aortic aneurYsm (TEDY): The study protocol for a randomized controlled trial. Trials2015, 16:274.

32. Yu X, Jiang D, Wang J, Wang R, Chen T, Wang K, Durgahee MSA, Wei X, Cao S: Metformin prescription and aortic aneurysm: systematic review and meta-analysis. Heart2019, 105:1351-1357.

33. Baxter BT, Matsumura J, Curci J, McBride R, Blackwelder WC, Liu X, Larson L, Terrin ML: Non-invasive Treatment of Abdominal Aortic Aneurysm Clinical Trial (N-TA(3)CT): Design of a Phase llb, placebocontrolled, double-blind, randomized clinical trial of doxycycline for the reduction of growth of small abdominal aortic aneurysm. Contemp Clin Trials2016, 48:91-98.

34. Abdul-Hussien $\mathrm{H}$, Hanemaaijer R, Verheijen $\mathrm{JH}$, van Bockel JH, Geelkerken RH, Lindeman JH: Doxycycline therapy for abdominal aneurysm: Improved proteolytic balance through reduced neutrophil content. J Vasc Surg2009, 49:741-749.

35. Kobeissi E, Hibino M, Pan H, Aune D: Blood pressure, hypertension and the risk of abdominal aortic aneurysms: a systematic review and meta-analysis of cohort studies. Eur J Epidemio/2019, 34:547555.

36. Malhotra J, Malvezzi M, Negri E, La Vecchia C, Boffetta P: Risk factors for lung cancer worldwide. European Respiratory Journal2016, 48:889.

37. Sakalihasan N, Michel J-B, Katsargyris A, Kuivaniemi H, Defraigne J-O, Nchimi A, Powell JT, Yoshimura K, Hultgren R: Abdominal aortic aneurysms. Nature Reviews Disease Primers2018, 4:34.

38. Force USPST: Screening for Abdominal Aortic Aneurysm: US Preventive Services Task Force Recommendation Statement. JAMA2019, 322:2211-2218.

\section{Tables}

Table 1 Baseline characteristics 


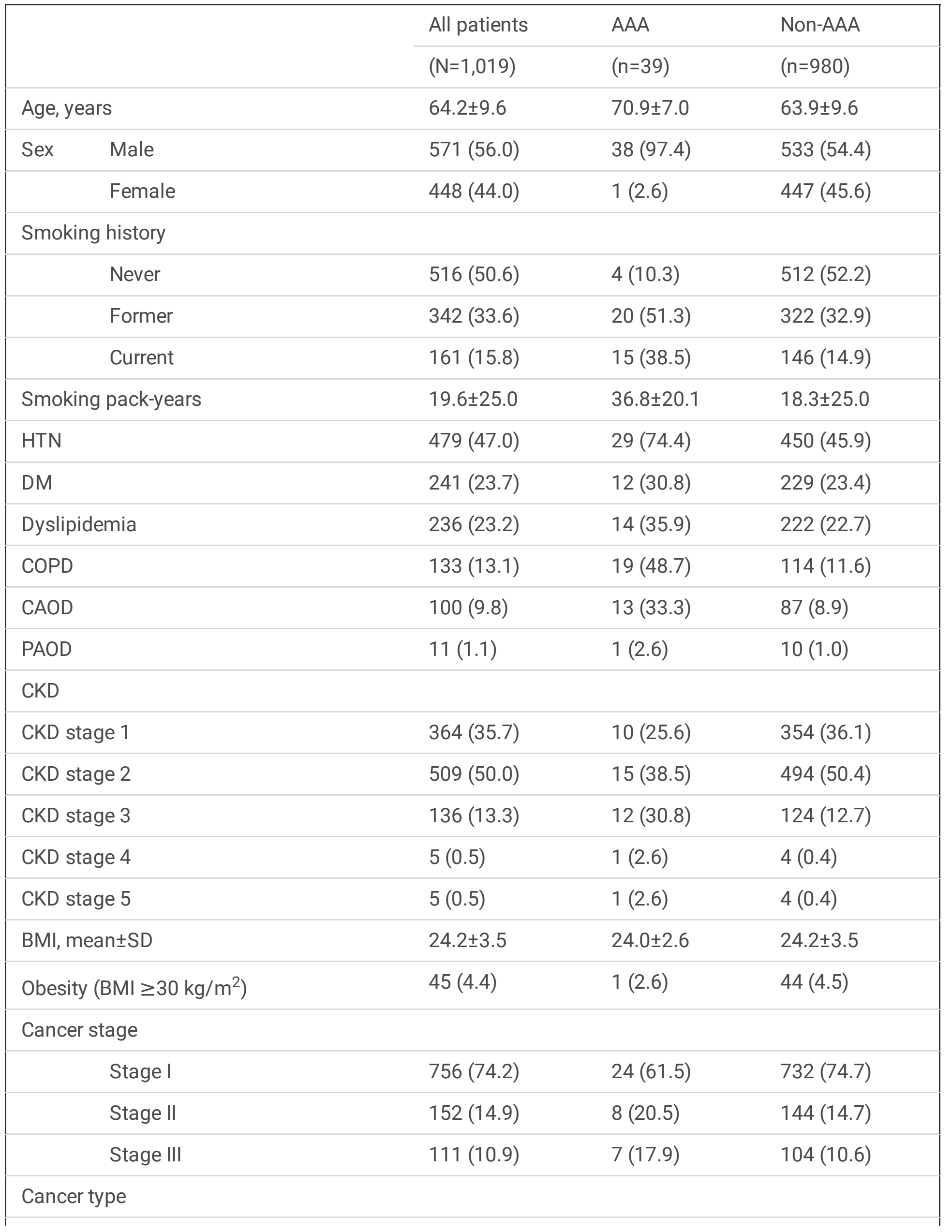




\begin{tabular}{|c|c|c|c|}
\hline Adenocarcinoma & $834(81.8)$ & $24(61.5)$ & $810(82.7)$ \\
\hline Squamous carcinoma & $152(14.9)$ & 13 (33.3) & $139(14.2)$ \\
\hline Other (non-small cell) & $33(3.2)$ & $2(5.1)$ & $31(3.2)$ \\
\hline \multicolumn{4}{|c|}{$\begin{array}{l}A A A \text {, abdominal aortic aneurysm; } B M I \text {, body max index; } H T N \text {, hypertension; } D M \text {, diabetes mellitus; } \\
C O P D \text {, chronic obstructive pulmonary disease; } C A O D \text {, coronary artery obstructive disease; } C K D \text {, } \\
\text { chronic kidney disease }\end{array}$} \\
\hline \multicolumn{4}{|c|}{$\begin{array}{l}\text { Categorical variables are presented as } n(\%) \text {. Pearson } \chi^{2} \text { test was used to determine significant } \\
\text { differences }(P<0.05) \text {. }\end{array}$} \\
\hline \multicolumn{4}{|c|}{$\begin{array}{l}\text { Continuous variables are presented as mean } \pm S D \text {. Student } t \text {-test was used to determine significant } \\
\text { differences }(P<0.05) \text {. }\end{array}$} \\
\hline
\end{tabular}

Table 2 Rates of abdominal aortic aneurysm (AAA) in patients with a positive smoking history (current or former) vs. non-smokers

\begin{tabular}{|lcll|}
\hline & Smoker & Non-smoker & Total \\
\hline AAA & 35 & 4 & 39 \\
\hline No AAA & 468 & 512 & 980 \\
\hline Prevalence, \% (n/total) & $\mathbf{7 . 0 \% ( 3 5 / 5 0 3 )}$ & $0.8 \%(4 / 516)$ & 1,019 \\
\hline $\begin{array}{l}\text { OR, 9.57; 95\%, Cl 3.38-27.14, P<0.001 } \\
\text { Values are reported as n. }\end{array}$ & \\
Pearson $\chi^{2}$ test was used to determine significance $(\mathrm{P}<0.05)$ & \\
\hline$A A A$, abdominal aortic aneurysm; OR, odds ratio; $C l$, confidence interval \\
\hline
\end{tabular}

Table 3 Comparison of baseline characteristics and AAA prevalence between lung cancer and control groups 


\begin{tabular}{|llll|}
\hline & Lung cancer & Control & P value \\
\hline Male sex & $56.0(571 / 1,019)$ & $57.5(1666 / 2,899)$ & 0.427 \\
\hline Age, years & $64.2 \pm 9.6$ & $54.4 \pm 10.3$ & $<0.001$ \\
\hline Smoker & $49.4(503 / 1,019)$ & $47.3(1378 / 2,899)$ & 0.070 \\
\hline Former & $33.6(342 / 1,019)$ & $27.6(800 / 2,899)$ & \\
\hline Current & $15.8(161 / 1,019)$ & $19.9(578 / 2,899)$ & \\
AAA & $3.8(39 / 1,019)$ & $0.2(6 / 2,899)$ & $<0.001$ \\
\hline Odds ratio [OR] for AAA, 19.19; 95\% Cl, 8.10-45.46 & \\
Categorical variables are reported as percentage (n/N). & \\
Continuous variables (i.e., age) are reported as mean $\pm S D$ & \\
Pearson $\chi^{2}$ test was used to determine significance $(\mathrm{P}<0.05)$ & \\
AAA, abdominal aortic aneurysm; OR, odds ratio; $C l$, confidence interval \\
\hline
\end{tabular}

Table 4 Univariable and multivariable logistic regression analysis of several risk factors for the presence of abdominal aortic aneurysm (AAA) in lung cancer and control groups 


\begin{tabular}{|c|c|c|c|c|c|c|c|c|}
\hline \multirow[b]{3}{*}{ Lung cancer } & \multicolumn{4}{|c|}{ Univariable analysis } & \multicolumn{4}{|c|}{ Multivariable analysis } \\
\hline & \multirow{2}{*}{$\begin{array}{l}\text { OR } \\
19.19\end{array}$} & \multicolumn{2}{|c|}{$95 \%$ Cl for OR } & \multirow{2}{*}{$\begin{array}{l}P \\
<0.001\end{array}$} & \multirow{2}{*}{$\begin{array}{l}\text { Adjusted } \\
\text { OR } \\
10.78\end{array}$} & \multicolumn{2}{|c|}{$\begin{array}{l}95 \% \mathrm{Cl} \text { for adjusted } \\
\text { OR }\end{array}$} & \multirow{2}{*}{$\begin{array}{l}P \\
<0.001\end{array}$} \\
\hline & & 8.10 & 45.46 & & & 4.11 & 28.26 & \\
\hline Sex, male & 33.75 & 4.65 & 245.23 & 0.001 & 30.75 & 4.15 & 227.61 & 0.022 \\
\hline Age & 1.14 & 1.10 & 1.18 & $<0.001$ & 1.09 & 1.04 & 1.14 & $<0.001$ \\
\hline $\begin{array}{l}\text { Age } \geq 60 \\
\text { years }\end{array}$ & 11.69 & 4.60 & 29.67 & $<0.001$ & & & & \\
\hline BMI & 1.02 & 0.80 & 1.30 & 0.883 & & & & \\
\hline Smoking, PY & 1.02 & 1.01 & 1.03 & $<0.001$ & & & & \\
\hline Smoking, $\mathbf{y} / \mathrm{n}^{\ddagger}$ & 9.57 & 3.38 & 27.14 & $<0.001$ & & & & $<0.001$ \\
\hline $\begin{array}{l}\text { Former } \\
\text { smoker }\end{array}$ & 9.92 & 3.32 & 28.76 & $<0.001$ & 6.05 & 2.02 & 18.13 & 0.001 \\
\hline $\begin{array}{l}\text { Current } \\
\text { smoker }\end{array}$ & 12.05 & 4.07 & 35.73 & $<0.001$ & 15.96 & 5.04 & 50.55 & $<0.001$ \\
\hline HTN & 7.40 & 3.74 & 14.66 & $<0.001$ & 2.50 & 1.14 & 5.47 & 0.022 \\
\hline DM & 2.32 & 1.19 & 4.52 & 0.013 & 0.52 & 0.24 & 1.12 & 0.096 \\
\hline Dyslipidemia & 1.80 & 0.98 & 3.34 & 0.060 & & & & \\
\hline CAOD & 12.13 & 6.21 & 23.67 & $<0.001$ & 2.74 & 1.21 & 6.20 & 0.016 \\
\hline \multicolumn{9}{|c|}{$\begin{array}{l}C l \text {, confidence interval; } O R \text {, odds ratio; } B M I \text {, body mass index; } P Y \text {, pack-years; } y / n \text {, yes } / \text { no; } \\
H T N \text {, hypertension; } D M \text {, diabetes mellitus; } C A O D \text {, coronary artery obstructive disease }\end{array}$} \\
\hline \multicolumn{9}{|c|}{ Bold P-values indicate statistical significance. } \\
\hline \multicolumn{9}{|c|}{$\begin{array}{l}\text { For continuous variables (age), the OR represents the change for every } 1 \text {-unit change in the } \\
\text { independent variable (years). Male sex, older age, smoking history, HTN, and CAOD were positive } \\
\text { independent risk factors for AAA. Adjusted odds ratios are represented by the OR. }\end{array}$} \\
\hline$\ddagger$ Former \& curr & ht smok & rs com & ared witl & never-sm & rers. & & & \\
\hline
\end{tabular}

Table 5 Univariable and multivariable logistic regression analysis of several risk factors for the presence of abdominal aortic aneurysm (AAA) in the lung cancer group 


\begin{tabular}{|c|c|c|c|c|c|c|c|c|}
\hline \multirow[b]{3}{*}{ Sex, male } & \multicolumn{4}{|c|}{ Univariable analysis } & \multicolumn{4}{|c|}{ Multivariable analysis } \\
\hline & \multirow{2}{*}{$\begin{array}{l}\text { OR } \\
31.87\end{array}$} & \multicolumn{2}{|c|}{$95 \% \mathrm{Cl}$ for OR } & \multirow{2}{*}{$\begin{array}{l}P \\
0.001\end{array}$} & \multirow{2}{*}{$\begin{array}{l}\text { Adjusted } \\
\text { OR } \\
13.24\end{array}$} & \multicolumn{2}{|c|}{$\begin{array}{l}95 \% \mathrm{Cl} \text { for adjusted } \\
\text { OR }\end{array}$} & \multirow{2}{*}{$\begin{array}{l}P \\
0.020\end{array}$} \\
\hline & & 4.36 & 233.03 & & & 1.49 & 117.48 & \\
\hline Aget & 1.10 & 1.05 & 1.15 & $<0.001$ & 1.10 & 1.04 & 1.15 & $<0.001$ \\
\hline Age $\geq 60$ yrs & 17.33 & 2.37 & 126.83 & 0.005 & & & & \\
\hline Obesity & 0.56 & 0.08 & 4.17 & 0.571 & & & & \\
\hline Smoking, PY & 1.02 & 1.01 & 1.03 & $<0.001$ & & & & \\
\hline Smoking, $y / n^{\ddagger}$ & 9.57 & 3.38 & 27.14 & $<0.001$ & & & & 0.021 \\
\hline Former smoker & 7.95 & 2.69 & 23.47 & $<0.001$ & 1.72 & 0.52 & 5.76 & \\
\hline Current smoker & 13.15 & 4.30 & 40.23 & $<0.001$ & 4.20 & 1.20 & 14.62 & \\
\hline HTN & 3.15 & 1.65 & 7.09 & 0.001 & & & & 0.179 \\
\hline DM & 1.46 & 0.73 & 2.92 & 0.289 & & & & \\
\hline Dyslipidemia & 1.91 & 0.98 & 3.74 & 0.058 & & & & \\
\hline COPD & 7.22 & 3.74 & 13.93 & $<0.001$ & & & & \\
\hline CAOD & 5.13 & 2.55 & 10.35 & $<0.001$ & 3.13 & 1.48 & 6.62 & 0.003 \\
\hline PAOD & 2.55 & 0.32 & 20.45 & 0.377 & & & & \\
\hline cancer stage & & & & 0.0178 & & & & \\
\hline CKD stage ${ }^{*}$ & & & & 0.004 & & & & 0.384 \\
\hline stage2 & 1.08 & 0.48 & 2.42 & 0.862 & & & & \\
\hline stage3 & 3.43 & 1.44 & 8.12 & 0.005 & & & & \\
\hline stage4 & 8.85 & 0.91 & 86.49 & 0.061 & & & & \\
\hline stage5 & 8.85 & 0.91 & 86.49 & 0.061 & & & & \\
\hline $\begin{array}{l}\text { Cancer } \\
\text { pathology }\end{array}$ & & & & 0.005 & & & & 0.912 \\
\hline SCC & 3.16 & 1.57 & 6.35 & 0.001 & & & & \\
\hline others & 2.177 & 0.49 & 9.63 & 0.305 & & & & \\
\hline $\begin{array}{l}\mathrm{Cl} \text {, confidence in } \\
\mathrm{HTN} \text {, hypertensi } \\
\text { coronary artery o } \\
\text { carcinoma }\end{array}$ & $\begin{array}{l}\text { al; } O R \\
\text { M, di } \\
\text { uctiv }\end{array}$ & $\begin{array}{l}\text { ds ro } \\
\text { tes r }\end{array}$ & $\begin{array}{l}P Y, \mathrm{pc} \\
\text { itus; } \mathrm{C} \\
A O D, \mathrm{p}\end{array}$ & $\begin{array}{l}\text { years; } \\
D \text {, chron } \\
\text { pheral a }\end{array}$ & $\begin{array}{l}\text { yes/no; } \\
\text { obstructive } \\
\text { rial occlus }\end{array}$ & Imo & $\begin{array}{l}\text { sease; } C A C \\
C \text {, squam }\end{array}$ & s cell \\
\hline
\end{tabular}


Bold P-values represent statistical significance.

For continuous variables (age), OR represents the change for every 1-unit change in the independent variable (years). Male sex, older age, smoking history, and CAOD were positive independent risk factors for AAA. Adjusted odds ratios are represented by the OR.

† Age at the time of surgery

‡ Former \& current smoker, compared to never-smoker

* Compared with CKD stage 1

${ }^{€}$ Compared with adenocarcinoma 